\title{
Pachas Maceda, Sofía (2019). Zoila Aurora Cáceres y la ciudadanía femenina. La correspondencia de Feminismo Peruano. Lima: Jurado Nacional de Elecciones, Fondo Editorial Universidad Nacional Mayor de San Marcos, Centro de la Mujer Peruana Flora Tristán.
}

En su estudio preliminar, Sofía Pachas señala que el "mensaje que deja la historia de Zoila Aurora Cáceres y el colectivo Feminismo Peruano es el de la lucha sin tregua, con valentía y persistencia, batalla que es imposible ignorar y que hoy, ad portas del Bicentenario de la Independencia del Perú, reclama ser contada en su verdadera dimensión". Este libro cumple a cabalidad el propósito que destaca la autora a través de una profunda investigación, donde se entrelazan las voces de quien relata con la de Zoila Aurora Cáceres y las de otras mujeres, gracias a una importante selección de cartas y documentos.

Cada aspecto de la vida de Zoila Aurora Cáceres, precursora del movimiento sufragista femenino, escritora, periodista, viajera, aparece en su contexto histórico. La fundación en 1924 de la organización Feminismo Peruano; las acciones que emprendió en los años previos a 1931, fecha de la Asamblea Constituyente; cuando en 1930 asesoró la organización del primer Sindicato de Costureras, y un año después el de las trabajadoras de la Compañía Peruana de Teléfonos, lo que también permite una aproximación a los movimientos que conformaron la sociedad civil de entonces.

En su lucha por lograr el sufragio femenino implementó varias acciones y dirigió numerosas cartas solicitando el apoyo necesario. Gestión que nos permite conocer el pensamiento de personalidades de la época como: Jorge Basadre, José de la Riva-Agüero y Osma, Dora Mayer, Luis Antonio Eguiguren, José Antonio Encinas, Miguelina Acosta, Luis Alberto Sánchez, Luis Alayza Paz Soldán, entre otros, que están comprendidas en el libro.

Ardua y difícil tarea la de cambiar una mentalidad asentada durante siglos, y plasmada en la primera Constitución (1826) de la República, que 
estipulaba en su Art. 14. ${ }^{\circ}$ los requisitos para ser ciudadanos: "Ser peruano. Ser casado, o mayor de veinticinco años. Saber leer y escribir. Tener algún empleo o industria o profesar alguna ciencia o arte". Las Constituciones de 1828, 1834 y 1839 son aún mucho más explícitas al establecer en el Art. 4. ${ }^{\circ}$ "Son ciudadanos peruanos todos los hombres libres nacidos en el territorio". Mientras que el Código Civil de 1852, además de no reconocerlas como ciudadanas, en su Art. 28 señala expresamente que las mujeres casadas dependen de sus maridos al igual que los hijos menores dependen de sus padres. Recién en la Constitución Política de 1933, y gracias a la lucha de las mujeres, el Art. 86 les otorgó el voto en elecciones municipales, derecho que no pudieron ejercer hasta 1963 debido a las interrupciones del proceso democrático.

Otro importante tema tratado en el libro es que el feminismo que defendía Zoila Aurora Cáceres, aunque resulte paradójico, era un feminismo católico conocido como marianismo, que situaba la maternidad como la principal misión de la mujer. El feminismo católico se oponía al sufragio femenino porque sostenía que con esta acción las mujeres podrían masculinizarse. Es interesante observar aquí la contradicción que vivió la propia Zoila Aurora Cáceres.

Esta generalizada visión de que las mujeres no requerían ni ser ciudadanas ni tener acceso a la educación está expresada también desde los primeros años de la República. Basta señalar que en la primera escuela destinada a las mujeres, establecida por la Sociedad Patriótica llamada Escuela Central Lancasteriana, solo podían estudiar hasta tercero de primaria y los cursos incluían catecismo, caligrafía y labores. A finales de 1830, los cursos se ampliaron con la incorporación de gramática, dibujo, música y bordado. Pero la propuesta de incluir el curso de matemáticas en 1840 originó tal debate que concluyó con su remoción, quedando solo la religión e instrucción doméstica como base de la educación femenina durante varias décadas.

Sofía Pachas también aborda en el libro la importancia que tuvieron los padres en la vida de Zoila Aurora Cáceres, hija del mariscal Andrés Avelino Cáceres, héroe de la Guerra del Pacífico, y de Antonia Moreno. Su infancia estuvo 
marcada por la guerra, cuyos recuerdos aparecen en su libro La princesa Suma Tica, en el que revela la admiración por el patriotismo de su madre. En efecto, Antonia Moreno acompañó con sus hijas a Cáceres durante las difíciles y duras jornadas de la Campaña de la Breña. También en el exilio y en las misiones diplomáticas en Europa.

Cuando en 1895 el presidente Andrés Avelino Cáceres fue derrocado por Nicolás de Piérola y tuvo que exilarse, Zoila Aurora viajó con su padre a Buenos Aires, donde en 1895 publicó "La emancipación de la mujer" en la revista Búcaro Americano, que dirigía Clorinda Matto de Turner. El artículo está firmado con el seudónimo de Eva Evangelina, y allí escribió: “Triste, tristísima es la condición de la mujer sud-americana; ofuscada por el pasajero amor del hombre querido, no medita en el lamentable rol que desempeña en la humanidad. Muchas todavía asumen un papel similar a las antiguas esclavas de oriente y con frecuencia están prontas a criticar a sus hermanas que se dedican a las ciencias o a las letras o trabajan".

Posteriormente, viajó con su padre a varios países donde este ejerció funciones diplomáticas. En París, Zoila Aurora Cáceres estudió en la Escuela de Altos Estudios Sociales de La Sorbona, graduándose en 1902 con la tesis Feminismo en Berlín. Y fue la primera mujer de habla española que dictó una conferencia en esa universidad, titulada "El oro del Perú". Aquí también conoció, en 1906, al escritor guatemalteco Enrique Gómez Castillo, unión que solo duró diez meses, según narra en su libro Mi vida con Enrique Gómez Castillo. Tres años después, en 1909, publicó Mujeres de ayer y hoy donde, como señala Sofía Pachas, reafirma su actividad literaria y posteriormente su labor como activista por los derechos de las mujeres. También ese año fundó la "Unión Literaria de los Países Latinos". Posteriormente viajó a Italia y Alemania donde su padre ocupaba el cargo de Representante del Perú. La admiración que sintió por él está expresada en la coautoría de su libro de narración histórica, La Campaña de la Breña. Memorias del mariscal del Perú D. Andrés A. Cáceres.

En 1911 publicó Oasis de arte, un libro de viajes donde se refleja la formación de las mujeres de letras en el Perú. Es importante tener en cuenta que, 
desde el comienzo de la escritura de la historia y aún antes cuando la transmisión oral registraba los hitos y las creencias fundamentales, los viajes siempre fueron territorio masculino, unidos a la aventura, la audacia y el valor. Por ello, este libro también reafirma la actitud contestataria de la escritora.

Sofía Pachas nos ha entregado un significativo aporte con este libro al relatar, a través de la vida de Zoila Aurora Cáceres, la lucha de las mujeres por lograr el sufragio, al mismo tiempo que refiere etapas importantes de la vida de Zoila Aurora, de sus viajes, y de su entorno social e intelectual. La investigación está sustentada por documentos de la escritora y de la época, así como por fuentes bibliográficas adecuadas para tratar el tema. Así mismo, porque a través de su investigación y de las cartas es posible acercarse a la historia de las mujeres como elemento transformador de ellas mismas; el hecho de saber que se tiene una historia propia constituye un paso decisivo para su emancipación, puesto que una nueva historia significa cambiar todo un andamiaje de ideas y creencias, así como transformar las actividades femeninas en experiencias definidas y trascendentes. No es muy difícil imaginar que entonces nuestras experiencias y vivencias serán valoradas en el curso del desarrollo de la humanidad, la cultura y la civilización.

\section{Sara Beatriz Guardia}

Centro de Estudios la Mujer en la Historia de América Latina, Lima, Perú Contacto: sarabeatriz.guardia@gmail.com 